\title{
NOTAS PARA UMA PESQUISA SOBRE LIBERDADE DE EXPRESSÃO NO MUNDO DO TRABALHO
}

\author{
Notes for research on freedom of expression in the world of work \\ Notas para la investigación sobre la libertad de expresión em el mundo del \\ trabajo
}

Fernando Felício Pachi Filho

Professor de Comunicação na Faculdade de Tecnologia Termomecanica

ffpachi@yahoo.com.br

\begin{abstract}
Resumo
Neste artigo, refletimos sobre a realização de um estudo que visa mapear e definir as possibilidades de liberdade de expressão no mundo do trabalho, a partir do contato com organizações que se manifestam como alinhadas aos princípios de direitos humanos. $\mathrm{O}$ referencial teórico adotado inclui o binômio comunicação e trabalho e aportes da sociologia do trabalho. Do ponto de vista metodológico, nos valemos de notas realizadas em diário de pesquisa. A análise dos registros demonstra que o acesso a informações para além do discurso autorizado e divulgado pelas organizações se revela problemático e contraditório com as declarações públicas de apoio aos direitos humanos. Tal dificuldade aponta para um controle cotidiano característico da sociedade contemporânea em que a expressão de trabalhadores é vista como ameaça à estabilidade do discurso empresarial.
\end{abstract}

Palavras-chave: Liberdade de expressão. Comunicação. Trabalho.

\begin{abstract}
In this article, we reflect on the realization of a study that aims to map and define the possibilities of freedom of expression in the world of work, from the contact with organizations that manifest themselves as aligned with the principles of human rights. The theoretical framework adopted includes the binomial communication and work and contributions from the sociology of work. From a methodological point of view, we use notes made in a research diary. Analysis of the records shows that access to information beyond authorized and published discourse by organizations is problematic and contradictory to public statements in support of human rights. Such difficulty points to a daily control characteristic of contemporary society in which the expression of workers is seen as a threat to the stability of corporate discourse.
\end{abstract}

Key words: Freedom of expression. Communication. Work. 


\section{Resumen}

En este artículo, reflexionamos sobre la realización de un estudio que tiene como objetivo mapear y definir las posibilidades de libertad de expresión en el mundo del trabajo, desde el contacto con organizaciones que se manifiestan alineadas con los principios de los derechos humanos. El marco teórico adoptado incluye el binomio comunicación y trabajo y las contribuciones de la sociología del trabajo. Desde un punto de vista metodológico, utilizamos notas hechas en un diario de investigación. El análisis de los registros muestra que el acceso a la información más allá del discurso autorizado y revelado por las organizaciones es problemático y contradictorio con las declaraciones públicas en apoyo de los derechos humanos. Dicha dificultad apunta a un control diario característico de la sociedad contemporánea en el que la expresión de los trabajadores es vista como una amenaza para la estabilidad del discurso corporativo.

Palabras clave: Libertad de expresión. Comunicación. Trabajo.

\section{INTRODUÇÃO}

A liberdade de expressão, consagrada nas constituições de matriz liberal, é considerada um dos valores que dão sustentação para a construção de democracias pluralistas e para a elaboração de novos parâmetros para a dignidade humana (FREITAS; CASTRO, 2013). Seu exercício permite aos seres humanos externarem seu modo de ser, sua totalidade moral e intelectual. Por meio do exercício da liberdade de expressão, garante-se o funcionamento do Estado democrático de direito e a sua afirmação política. No caso brasileiro, a opção por resguardar os direitos individuais e sociais é uma marca da Constituição Federal de 1988 (2020), que tem como um de seus fundamentos a dignidade da pessoa humana.

Como pressuposto para a dignidade humana, a liberdade de expressão deve ser constituída como regra e sua limitação é a exceção. Entretanto, sabemos da dificuldade de efetivação e sustentação do ideal democrático (CARVALHO, 2017; 2019) em nosso país e acreditamos que os sentidos para a liberdade de expressão permanecem opacos e pouco explorados na sua historicidade no Brasil, sobretudo se considerarmos as várias esferas sociais. Ainda que o arcabouço das sociedades democráticas liberais também abarque as relações de trabalho na proteção desse direito (MELLO, 2015), a investigação acerca da liberdade de expressão no mundo do trabalho é cercada de restrições e sua apreensão torna-se difícil. Nesse ponto, cabe observar que ainda nos carecem mapeamento e definição de suas possibilidades, devido ao debate incipiente entre os pesquisadores e ausência de dados disponíveis para estudo. Por essa razão, acreditamos ser necessário desenvolver pesquisas 
para a compreensão dos limites que se estabelecem para a liberdade de expressão em contextos laborais.

Neste artigo, descrevemos e analisamos as limitações de acesso ao campo de estudo numa pesquisa exploratória e empírica, desenvolvida entre 2015 e 2018 sobre liberdade de expressão no mundo do trabalho, com base em registros realizados em diário de campo a partir do contato com organizações de portes e tamanhos variados. O objetivo da pesquisa, da qual apresentamos este recorte, foi observar a liberdade de expressão na relação entre trabalhadores e organizações, no contexto contemporâneo altamente contraditório de desenvolvimento dos regimes de produção, marcados pela racionalização administrativa, pela pressão por qualidade e competitividade e pela adoção generalizada de tecnologias de informação e comunicação (SANTOS, 2000; ANTUNES, 2011; HARVEY, 2008), que também servem para o controle das atividades de trabalho e dos padrões comportamentais dos trabalhadores. Paralelamente, desenvolve-se um cenário em que os indivíduos são interpelados ideologicamente por valores como autonomia, liberdade e flexibilidade (BOLTANSKI; CHIAPELLO, 2009).

O olhar inicial para práticas de gestão empresarial, com vista a estabelecer o funcionamento do sistema da liberdade de expressão e suas interdições, se justifica devido às significativas modificações por que passam as organizações e seus impactos no mundo do trabalho. Nesse contexto, aprimoram-se técnicas de gerenciamento que objetivam a mobilização permanente da força de trabalho, a cooperação constrangida, a administração por metas, a qualidade total (ANTUNES, 2009; 2011) e uma governança em prol de uma "relação equilibrada e transparente" com seus públicos (FREEMAN, 2000), pautada por compromissos e resultados. Nesse cenário, a comunicação é instrumentalizada para alinhamento dos propósitos da organização (REBECHI; FIGARO, 2013). A partir dessa compreensão, o questionamento acerca dos sentidos que se formam sobre liberdade de expressão na relação entre organizações e trabalhadores nos parece necessário para compreender a abrangência social desse conceito.

Inicialmente, apresentamos neste artigo o enquadramento teórico que sustenta a pesquisa, que envolve o binômio comunicação e trabalho, desenvolvido por Figaro (2009; 2018), e aportes da sociologia do trabalho. Em seguida, abordamos o uso de diário de pesquisa como instrumento para coleta e registro de dados e observações; a análise realizada, 
na qual expomos a dificuldade de acesso a dados das organizações para fins de pesquisa acadêmica. As observações nos demonstram que a expressão dos trabalhadores pode ser compreendida pelas organizações como risco a suas marcas e produtos (BARRY, 2007). Como consequência, a dificuldade de acesso aos trabalhadores é um sinal da existência da cultura do silêncio, tal qual abordada por Lima (2013).

\section{REFERENCIAL TEÓRICO}

O delineamento teórico que dá sustentação a esta pesquisa parte da interface entre a sociologia do trabalho, na vertente elaborada por autores como Antunes $(2009 ; 2011 ; 2018)$ e Linhart (2000; 2007; 2013), e o binômio comunicação e trabalho, desenvolvido por Figaro (2009; 2018), que nos dá condições de interpretar as relações de trabalho como fenômenos comunicacionais e de compreender as redes de sentido que se formam no trabalho, tomado como espaço de mediação. Nesse espaço, há reelaborações de significados pelos sujeitos em seu meio cultural no confronto com as situações de trabalho em ambientes que têm sido historicamente controlados, determinados por regras, normas e processos (BOUTET, 2008; BRAVERMAN, 2012) que nem sempre privilegiam os direitos individuais, entre eles a liberdade de expressão.

Antunes e Linhart indicam caminhos para pensar a liberdade de expressão. Cumpre, porém, compreendermos que o discurso formado no interior dessas perspectivas se insere nas questões sociais, marcadas pela luta de classes e assim procuramos considerá-los. Reafirmamos também a centralidade da categoria trabalho como base para a análise sociológica e para a formação de uma perspectiva materialista de compreensão da evolução sócio-histórica. Como explica Cardoso (2011), a categoria trabalho consolidou-se ao longo da história do pensamento social como base para análise e compreensão da vida em sociedade, cujos conflitos se intensificaram na forma capitalista de produção industrial.

Antunes $(2009 ; 2011 ; 2018)$ sustenta que as crises geradas no sistema capitalista têm afetado intensamente o mundo do trabalho, provocando alterações na materialidade e na subjetividade dos que vivem do trabalho. Nas últimas décadas, a manutenção do modo de produção capitalista passou a depender da revolução tecnológica baseada na informática e na robótica, que fornecem a base para a globalização do capital, num quadro recessivo dominado pelo ideário neoliberal, que, entre outras soluções para a economia, prega a privatização, a 
desregulamentação e a flexibilização do regime produtivo. Com as mudanças na base tecnológica, aumenta o trabalho morto, que se concentra nos dispositivos tecnológicos, para ampliar incessantemente a produtividade do trabalho. Nesse processo, em que se buscam novos padrões de produtividade adequados à lógica do mercado, flexibiliza-se a produção incluindo modelos diferentes de gestão do trabalho. Gestão participativa, qualidade total, círculos de controle de qualidade, que têm na sua base o toyotismo, passam a ser largamente difundidos e adotados no mundo de forma variada. Boltanski e Chiapello (2009) explicam que esse modelo produtivo, que visa atender também a demandas dos trabalhadores por mais liberdade e flexibilidade, se dissemina e contribui para a formação do que os autores denominam de novo espírito do capitalismo.

A reestruturação produtiva em curso desde os anos 70 do século passado tornou mais complexa a realidade do trabalho e desorganizou o mundo do trabalho em diversos sentidos. Essa é a conclusão a que também chega Linhart (2000). Mudanças nas representações, nas relações sociais, ampliação do uso de técnicas informáticas, novas formas de organização do trabalho, incremento das atividades de serviços, redução dos efetivos, remodelagem dos tempos de trabalho e recurso cada vez mais sistemático às formas de emprego atípicas são alguns dos fatores que alteram, na visão dessa socióloga, o modo como o trabalho se realiza e a inserção dos trabalhadores no universo das empresas. Os gestores do trabalho devem buscar moldar os comportamentos incentivando as qualidades humanas, como a fidelidade e a confiança, e ajudar seus "colaboradores" a desenvolver sua personalidade com base nesses valores. A gestão moderna aposta na mobilização subjetiva, no envolvimento dos trabalhadores para investirem seus saberes, suas capacidades e sua iniciativa com objetivo de atingir as metas estabelecidas no plano da gestão. Por isso, conforme a autora, a "eficácia técnico-econômica do modelo repousa sobre os comportamentos individuais e coletivos." (LINHART, 2000, p. 27).

Aumentam-se as coerções, as exigências e as expectativas em relação aos trabalhadores, sem que a concepção de trabalho assalariado tenha sofrido mudanças fundamentais. Sua autonomia em relação ao que se deve fazer e às condições para fazê-lo continua restrita. Imposição de ideias e metas de produção num ambiente de trabalho em que se impede a formação de uma identidade dos coletivos acabam prejudicando o indivíduo, em vez de colocá-lo no centro do processo produtivo de fato. Esse modelo de gestão que mobiliza a subjetividade leva ao que Linhart (2013) chama de precarização subjetiva. 
Nesse contexto, a comunicação passa a fomentar a cooperação, a prevenção e resolução de conflitos, além de respaldar o sentimento de individualidade e identidade. Podese dizer que há uma inflação da comunicação nas organizações, que se utilizam de dispositivos variados como práticas participativas para formação nos valores requeridos, veículos de comunicação, canais para escuta dos trabalhadores, palestras, atividades de integração, entre outras. O resultado dessas práticas é uma aparência de democracia no interior das empresas.

A comunicação nas organizações, vista sob a ótica do que se configurou como comunicação interna no domínio das Relações Públicas, explicam Rebechi e Figaro (2013), é pensada no escopo de uma gestão alinhada às lógicas produtivas. Busca-se um controle social dos trabalhadores, inibindo reivindicações e contestações. Em suma, o objetivo é direcionar as atividades de trabalho, a partir do "fluxo de informações adequado" e, ao mesmo tempo, neutralizar conflitos e discursos que se contraponham à gestão do trabalho tal como ela se realiza. Há, portanto, um desejo de controle das relações de comunicação que entende o trabalho como problema a ser resolvido e fator de acumulação de capital.

Assim, devemos admitir que a abordagem da comunicação no mundo do trabalho não se confunde com as práticas de comunicação organizacional, campo legitimado na perspectiva de estudos organizacionais, no qual a comunicação se integra de modo instrumental às lógicas produtivas para aumentar a eficiência, a produtividade e propiciar a adesão dos trabalhadores a projetos empresariais. Tomados neste contexto, a administração, a comunicação e a tecnologia da informação se configuram assim como dispositivos de controle (AGAMBEN, 2005).

Tendo em vista o cenário descrito acima, em que a comunicação é entendida como parte constitutiva do mundo do trabalho num momento em que sua importância é inegável e legitimada como fator determinante da reestruturação produtiva, cumpre considerá-la para além da dimensão organizacional ou instrumental. A constituição do binômio comunicação e trabalho, proposto por Figaro $(2009 ; 2018)$, promove o deslocamento da comunicação para o mundo do trabalho, gesto que permite pensá-la a partir de relações de sentido variadas e não padronizadas e/ou uniformizadas conforme se pretende na gestão dessa comunicação.

Ao abordarmos a relação comunicação e trabalho, partimos de uma concepção de comunicação não instrumental que não se coloca a serviço dos ditames do capital. O objetivo 
passa a ser a compreensão das relações de sentidos e dos processos comunicacionais que fazem parte do mundo do trabalho. A análise da comunicação a partir do trabalho exige mudança de enfoque e de lugar de observação. Deve-se compreender o que constitui o mundo do trabalho e como ele pode ser observado para além das relações contratuais que se estabelecem entre empregadores e trabalhadores. O mundo do trabalho, conforme define Figaro (2008), é uma categoria ampla, que ultrapassa o escopo das organizações. O mundo do trabalho, que inclui as organizações, é atravessado por discursos, valores e ideologias variadas, grupos sociais distintos que só podem ser identificados se considerarmos essa categoria, "difusa e complexa, característica e fundamento da sociedade, pois lugar privilegiado que abriga grande parte da atividade humana." (FIGARO, 2008, p. 93).

Assim, na perspectiva de Figaro (2008;2018), trabalho e comunicação são centrais na constituição das relações sociais, o que inclui os processos produtivos. A atividade de comunicação e trabalho são essenciais e indissociáveis para o ser humano, independentemente do modelo adotado para a organização da produção. A atividade de trabalho, que depende da ação do homem, é articulada pela atividade de comunicação, no trabalho social que caracteriza a própria espécie. O trabalho é tratado como espaço de mediação, focalizando o lugar onde se articula o sentido, ou seja, como os receptores, constituídos por uma história social complexa, formam diferentes sentidos a partir das mensagens que circulam no trabalho.

\section{DIÁRIO DE PESQUISA}

Para o perfil de pesquisa que realizamos, exploratório e empírico, adotamos como técnica o registro das observações em diário. Os estudos exploratórios servem para preparar o campo para pesquisas posteriores, contribuindo para abordagem de temas ou problemas ainda pouco estudados e ideias vagamente relacionadas com o problema de estudo, sobre o qual se tem muitas dúvidas ou que não tenha sido tratado anteriormente (SAMPIERI; COLLADO; LUCIO, 2006). Assim, essas pesquisas visam obter conhecimento inicial de um contexto, uma situação, uma variável ou conjunto de variáveis. Conforme explica Martino (2011), a pesquisa empírica contribui para alimentar a reflexão sobre o objeto e para o desenvolvimento teórico.

A elaboração de um diário de pesquisa representa um instrumento determinante para os estudos que se utilizam do método etnográfico para a compreensão de hábitos, comportamentos e atitudes de indivíduos. A eficácia do uso de um diário é determinada pela 
capacidade de observação dos comportamentos e manifestações culturais desenvolvida pelo pesquisador ao longo do contato com os grupos sociais que se configuram como sujeitos de sua pesquisa. No diário, devem ser registrados todos os dados coletados, acontecimentos presenciados, comportamentos e sentimentos dos participantes e do próprio pesquisador de modo a ter um acervo para a melhor compreensão de determinada realidade.

O diário de pesquisa se constitui como um estoque de materiais e registros que podem servir para apontar os caminhos das pesquisas, para aprofundar hipóteses ou mesmo para registro de insights que podem se transformar em novas pesquisas. Configuram-se como registros pessoais de observações, eventos, pensamentos, sentimentos, comportamentos específicos e atividades em determinado período de tempo (ZACCARELLI; GODOY, 2010).

Weber (2009) explica que no diário de pesquisa deve-se relacionar os eventos observados e acumular os materiais que serão usados para analisar práticas, discursos e posições dos entrevistados, além de atualizar as relações que foram nutridas entre o pesquisador e os sujeitos pesquisados, permitindo assim a objetivação da posição do observador. Desse modo, o diário de pesquisa permite descrever e analisar os fenômenos estudados e compreender os lugares ocupados pelo observador e pelo pesquisador, esclarecendo as atitudes de cada um. O diário também cumpre a função de garantir o distanciamento exigido numa pesquisa de campo e permite a análise do desenvolvimento da própria pesquisa.

\subsection{A dificuldade de entrada no campo}

Cavedon (2003) explica que a forma como o pesquisador é introduzido no campo é um ponto significativo para o início da interação com os participantes. Nesse sentido, nos momentos de interação o pesquisador deve ficar atento a como as relações são pautadas e ao modo como se inseriu no campo. Além disso, a observação deve considerar os motivos e intenções que integram as ações humanas.

Neste ponto, cabe uma reflexão sobre como procuramos entrar em nosso campo de pesquisa. Sabemos que desde fins dos anos 90 do século passado, as organizações passam a ser afetadas por discursos que enfatizam a necessidade de que elas repensem sua atuação social e ambiental e contribuam efetivamente para a criação de um ambiente de negócios pautado por valores éticos, socialmente justos e sustentáveis. Tais discursos, constituídos com base nesse universo de crenças, deram sustentação à formação de entidades que visam 
congregar organizações empresariais interessadas na promoção de conceitos como responsabilidade social, direitos humanos e sustentabilidade. Nesse sentido, acreditávamos que nossa abordagem deveria se iniciar por essas entidades, supostamente pela sensibilidade e abertura que poderiam demonstrar para a reflexão de um tema como liberdade de expressão, um dos direitos humanos reconhecidos internacionalmente. Além disso, acreditávamos na possibilidade de que, ao nos relacionarmos com representantes dessas entidades, teríamos mais facilidade de acesso à observação e entrevistas com trabalhadores das organizações associadas. Cumpre destacar que as fases posteriores da pesquisa incluíam resposta a questionário por parte das empresas, resposta a questionário por parte de amostra de trabalhadores e entrevistas com trabalhadores com objetivo de atingir a triangulação de métodos e dados de fontes distintas (DENZIN; LINCOLN, 2000).

As organizações associadas a essas entidades comprometem-se publicamente a apoiar temáticas de direitos humanos, característica que para nós serviu de critério para definição de organizações que seriam abordadas para a composição da amostra. Pelas razões descritas, procuramos contatar duas dessas entidades, ambas sediadas na cidade de São Paulo. A primeira delas (A) foi fundada no Brasil em fins dos anos 90 do século passado e procura disseminar temas de responsabilidade social empresarial, tendo em seu quadro de associados cerca de 500 organizações de vários setores, portes e tamanhos, algumas delas listadas entre as maiores do país, com prêmios e distinções públicas na área de responsabilidade socioambiental e direitos humanos. A segunda delas (B) é responsável por fomentar no mundo empresarial a discussão sobre direitos humanos e sustentabilidade desde 2001, tendo recebido a adesão de cerca de 800 organizações, também de vários portes e tamanhos. Em ambas as entidades, há grupos de trabalho sobre empresas e direitos humanos que se reúnem periodicamente para discussão de questões que afetam o cotidiano empresarial nesta área ${ }^{1}$.

Procuramos assim estabelecer contato com os organizadores desses grupos em 2016. $\mathrm{Na}$ ocasião, nosso objetivo era apresentar a pesquisa e iniciar um relacionamento para realizarmos a coleta de dados, que depende da participação de empresas e trabalhadores. Munidos de carta de apresentação da Escola de Comunicações e Artes da Universidade São Paulo (ECA-USP), estabelecemos contato com essas entidades e, apesar de haver abertura para o diálogo, os representantes das assessorias de comunicação de cada uma delas disseram

\footnotetext{
${ }^{1} \mathrm{O}$ acordo realizado para acompanhamento de atividades nestas entidades incluiu a preservação de suas identidades.
} 
não ter autonomia para decidir sobre a concessão de entrevistas ou mesmo autorização para fornecer contatos de associados. A contribuição para a pesquisa deveria ser decidida no âmbito da direção das entidades. Após alguma insistência, em ambas as entidades conseguimos agendar reuniões com os representantes da área de comunicação para apresentação prévia da pesquisa e de seus objetivos, de modo a facilitar o entendimento desses profissionais para que pudessem avaliar a proposta e argumentar em nosso favor. Apesar da manifestação de apoio, a resposta não foi alterada, ou seja, haveria necessidade de aprovação superior, o que exigiu de nós, a partir de então, uma rotina de contatos semanais até que houvesse uma resposta definitiva sobre a contribuição dessas entidades para a pesquisa. Passamos assim a ficar à mercê da agenda do corpo diretivo de cada entidade e das discussões internas a respeito de nosso projeto.

Notamos que o contato com observadores externos é regulado e necessita de sanção da hierarquia superior. Em ambas as entidades, observamos que não havia nenhum procedimento fechado para o atendimento a pesquisadores. Após vários contatos ao longo de dois meses de insistência, ficou definido em ambas as entidades que participaríamos de reuniões de trabalho dos grupos de direitos humanos, o que nos permitiria ao menos cumprir o objetivo de apresentar a pesquisa, convidar e estimular os representantes das organizações a participarem de nosso trabalho. Em ambas as entidades, nos foi observado que a oportunidade dada para a apresentação da pesquisa não se constituía em apoio direto à sua realização e que a participação no estudo deveria ser definida individualmente pelas organizações que integravam os grupos de direitos humanos.

Em ambas as reuniões, com a participação total de representantes de 12 organizações, filiadas a A, e 15 organizações, filiadas a B, a acolhida também se deu de modo cordial. Dispusemos de aproximadamente 20 minutos de apresentação, tempo no qual pudemos responder a eventuais dúvidas e questionamentos. Os representantes das organizações presentes às reuniões eram em sua maioria gestores na área de responsabilidade social, comunicação e recursos humanos. Apesar de não familiarizados com os procedimentos de uma pesquisa científica, demonstraram curiosidade. Muitos deles confessaram não ter refletido anteriormente sobre a questão da liberdade de expressão. Podemos assim observar que há um apagamento de temas relativos aos direitos civis, que são perceptíveis para esses profissionais apenas no que se refere a questões de gênero, em pauta na sociedade contemporânea. Tampouco nas considerações feitas estabeleciam-se vínculos entre questões 
de gênero e liberdade de expressão, fato que nos demonstrou precariedade conceitual para delimitação da abrangência desse direito.

As pautas discutidas, em ambas as reuniões, se referem a ações que as empresas realizavam para adoção de projetos nas áreas de direitos humanos, buscando o enquadramento às recomendações expressas na pesquisa realizada por John Ruggie (2014), em que os verbos respeitar, proteger e reparar se tornam os parâmetros que devem ser observadas por organizações no trato das questões de direitos humanos. Temas como auxílio aos refugiados, projetos de diversidade, em especial na questão de gênero, participação em eventos e fóruns internacionais, relatórios de sustentabilidade e direitos humanos dominam as pautas. Percebese, portanto, a preocupação em gerir os direitos humanos no interior das organizações e dar visibilidade a ações em curso, sem que haja uma reflexão mais detida sobre os fundamentos e características desses direitos. Observa-se que tais iniciativas buscam inserir-se em padrões modernos de gestão (BOLTANSKI; CHIAPELLO, 2020; ANTUNES, 2011).

Ao tratar do tema de nossa pesquisa, a liberdade de expressão no mundo do trabalho, nossa percepção foi inicialmente uma dificuldade dos participantes de compreender a inserção do tema no campo dos direitos humanos. Em segundo lugar, como suspeitávamos, uma dificuldade na conceituação de liberdade e, consequentemente, de liberdade de expressão, bem como dos parâmetros para respeito a este direito fundamental. A liberdade de expressão como proposta de reflexão era um tema novo para as organizações, não suficientemente agendado no debate social que prioriza as artes e o universo da comunicação midiática.

Para alguns dos participantes, o fato de que havia garantias legais já definidas para a liberdade de expressão era suficiente para atestar sua existência. Assim, as definições estabelecidas pela legislação bastavam para o enquadramento das empresas nos parâmetros de respeito aos direitos humanos na sociedade brasileira. Entretanto, nenhuma consideração foi feita sobre como respeitar o direito de expressão dos trabalhadores tampouco em relação às nossas variantes culturais e históricas, que situam a liberdade de expressão num campo de significados particulares. Como o cumprimento da lei era um aspecto defendido pelos participantes como elemento definidor de empresas que buscam a defesa dos direitos humanos, este fato por si era suficiente para que este preceito fosse seguido, não cabendo grandes discussões a respeito. Tanto na reunião em A quanto em B, alguns participantes relacionaram o tema com as redes sociais e a necessidade de controle para preservação da 
imagem das organizações e de segredos de mercado. Suas observações, porém, não visavam diretamente a preservação de direitos individuais, mas sim a proteção das organizações (BARRY, 2007). Alguns mencionaram a necessidade de criação de regras pelas próprias organizações.

Outros questionamentos demonstravam ceticismo em relação à viabilidade da pesquisa, mesmo porque não havia ganhos diretos para as organizações, como foi apontado por um participante na reunião em A. Por isso, no diálogo conosco sugeriu que oferecêssemos algum benefício para as empresas, de modo a "agregar valor " à proposta de parceria. Notemos que a sugestão visava adaptar a pesquisa ao universo empresarial, às suas preocupações mercadológicas, pragmáticas e de ganhos definidos. O que podíamos oferecer era um relatório analítico executivo com análise e interpretação dos dados obtidos, sem que houvesse identificação dos respondentes, conforme padrões éticos adotados na pesquisa (SANTOS; KARNOPP, 2017). Embora este procedimento já estivesse previsto, passamos a enfatizar a oferta em nossas abordagens posteriores, de modo a atender às expectativas de ganho das organizações.

Ao final das reuniões, pudemos perceber que há, no contexto das organizações, uma indefinição sobre o que é a liberdade de expressão e quais deveriam ser seus limites. Os significados para a liberdade de expressão parecem estar circunscritos ao discurso jurídico, que sintetiza as possibilidades para a definição deste direito e seria diretamente aplicado sem conflitos ao mundo do trabalho (MELLO, 2015). Outro aspecto que nos pareceu relevante foi a dificuldade de abordagem do tema em parâmetros diversos das intenções e práticas já divulgadas e aceitas pelas organizações, a exemplo de temas vinculados a direitos sociais e ao meio ambiente. Ademais, pudemos observar que a liberdade de expressão não integra as preocupações destas organizações. O tema só é discutido lateralmente em questões relacionadas às tecnologias de informação e comunicação no que se refere à necessidade de definir parâmetros de vigilância e sem considerar a expressão individual como direito.

Feito o primeiro contato durante as reuniões, a etapa seguinte foi a de cultivar o relacionamento com os representantes das organizações participantes e seguir contatando outros associados dessas entidades, convidando-as a participar da pesquisa. Em carta direcionada às organizações contatadas, após breve explanação da pesquisa e da metodologia a ser utilizada, assumimos o uso exclusivamente acadêmico e de tratamento agregado dos 
dados sem a nomeação dos nomes dos participantes, empresas e funcionários, mantendo assim confidencialidade exigida para o desenvolvimento do estudo. Dessa forma, iniciamos uma rotina de telefonemas, envio de e-mails, reuniões presenciais, conference calls para tentarmos formar uma amostra suficiente para nosso trabalho de colheita de dados.

Optamos por iniciar os contatos pelas áreas de comunicação e responsabilidade social, familiarizadas com as questões abordadas em nossa pesquisa. Em todos os casos, nenhum representante dessas áreas se declarou autônomo para aprovação da realização da pesquisa, assim como ocorreu nas entidades empresariais. Para uma tomada de decisão, conforme relatos de profissionais com os quais conversamos, a avaliação e aprovação deveria também ser feita pelas áreas de recursos humanos e jurídica, responsáveis por analisar o interesse para a organização da pesquisa e os riscos de participação. A recepção aos pesquisadores da parte dos assessores é acolhedora, como cumpre o ritual das atividades de relações públicas, porém o encaminhamento é complexo no interior da organização. Não é dada a prioridade ao assunto e, muitas vezes, a pesquisa é tratada apenas como uma demanda a ser respondida. Na maioria das organizações, não há procedimentos para o atendimento a pesquisadores. A recusa, pura e simples, é a prática mais adotada, ainda que não se revele diretamente nos contatos iniciais. Alguns assessores acreditavam que as informações públicas, sobretudo as disponíveis em relatórios, eram suficientes para a pesquisa científica, porque tais relatórios seguiam procedimentos internacionais e eram auditados.

Notamos que uma rede de controle do discurso da organização e de seus trabalhadores se forma (REBECHI; FIGARO, 2013). Conversar sobre liberdade é motivo de preocupação e de risco, mesmo que haja um compromisso formal de respeito à identidade de trabalhadores e da organização. Podemos observar que a expressão dos trabalhadores nas organizações, mesmo para fins de uma pesquisa científica, está subordinada pelo contrato de trabalho à organização e que as condições de produção do discurso sobre a liberdade de expressão são afetadas pela relação de dependência que se estabelece no contrato de trabalho (MELLO, 2015). Em média, entre o contato inicial e uma resposta da organização, despendemos em torno de 45 dias. Em alguns casos, a negociação se estendeu por quase três meses, sendo que a fase de coleta de dados se iniciou efetivamente em 2017.

Das 43 organizações contatadas, 7 confirmaram a participação na pesquisa, 9 não deram resposta à nossa solicitação, mesmo após inúmeras tentativas de contato e solicitações 
de retorno, 1 desistiu de participar ${ }^{2}$ e as outras 26 declinaram do nosso convite (Figura 1), porém apresentaram justificativas (Figura 2). Acreditamos que esses números apontam não só a dificuldade de realização de uma pesquisa no perfil como a definimos, mas também a falta de preparo e disposição interna para lidar com demandas sociais advindas da universidade, sobretudo nas áreas de humanidades, marcadas pelos aportes críticos em relação às organizações da sociedade. Outro aspecto é o fato de a pesquisa acerca da liberdade de expressão não contribuir diretamente para os interesses imediatos das organizações, pautadas pela necessidade de posicionamento de suas marcas em temas que são valorizados mais diretamente na agenda social, como a defesa do meio ambiente ou mesmo da diversidade de gênero.

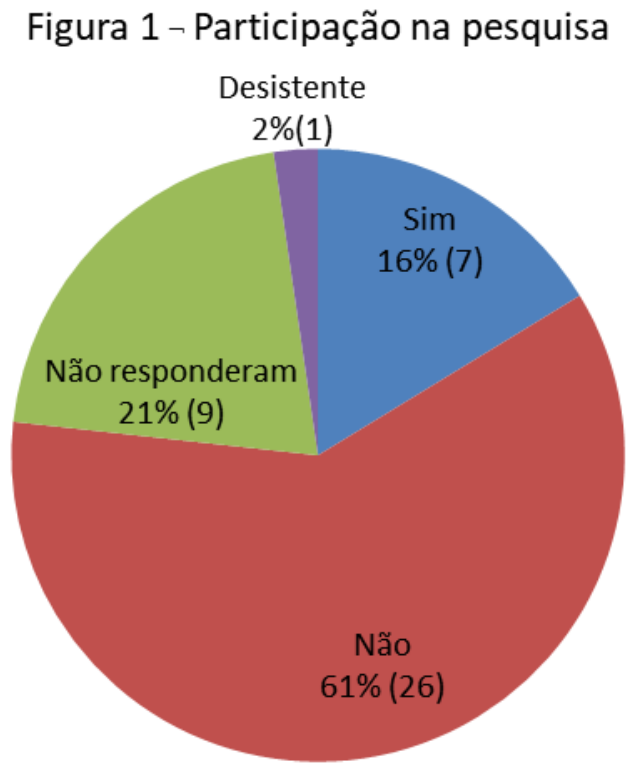

Fonte: Elaboração do autor (2020)

\footnotetext{
${ }^{2}$ A desistência se deveu ao fato de que o gestor da área de comunicação se desvinculara da empresa e não havia definição sobre sua substituição.
} 
Figura 2 - Razões para não participar da pesquisa

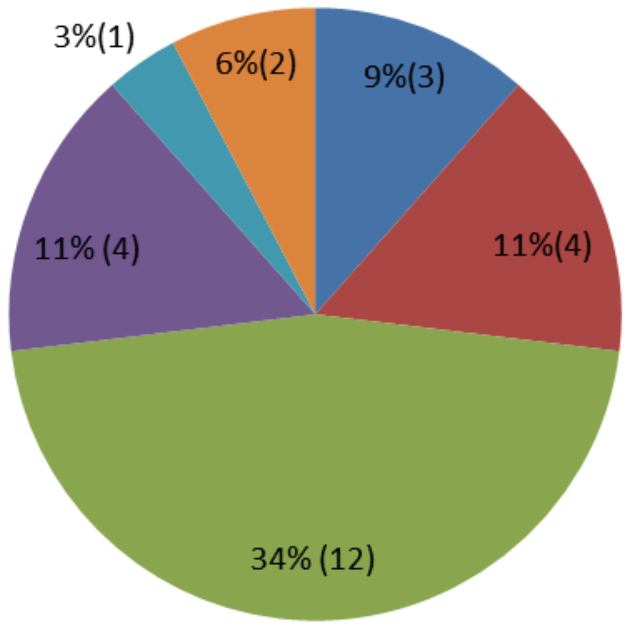

• Não autorizado pela direção

- Política da empresa de não participar

- Falta de disponibilidade para atender pesquisadores

- Reestruturação interna/crise econômica

- Manutenção de segredos industriais

não ofereceu justificativa

Fonte: Elaboração do autor (2020)

Consideremos para o momento as razões apontadas para a não participação na pesquisa, entre elas estão a crise econômica, reestruturação interna, falta de tempo disponível para se dedicar ao atendimento de pesquisadores, política interna de não participação em pesquisas. Não podemos determinar a veracidade das razões apontadas. No entanto, cabe aqui algum questionamento acerca dessas justificativas. Crise econômica e reestruturação interna se referem ao ambiente contemporâneo dos negócios em que organizações e trabalhadores precisam se ajustar para não perder competitividade e não reduzir a lucratividade. Sabemos que demissões ocorrem, intensificam-se as rotinas de trabalho, promove-se substituição de tecnologias, situações que fazem recuar reivindicações de trabalhadores. Nesse ambiente, também aumenta a crítica às organizações por parte de trabalhadores (LINHART, 2013).

Participar de uma pesquisa, cujo tema é liberdade de expressão, é abrir um canal para que trabalhadores exerçam um direito de crítica e se aproveitem da oportunidade de escuta externa à organização. Há um risco à imagem que as organizações passam a considerar na fala dos próprios trabalhadores (BARRY, 2007). Não participar de uma pesquisa é uma forma de eliminar o risco e interditar a expressão. Podemos observar assim que os mecanismos de silenciamento se dão naquilo que pode escapar ao controle da organização, ou seja, a 
expressão dos trabalhadores, capazes de estabelecer outros sentidos para a realidade que vivem. Orlandi (2015) nos ensina que a censura busca impedir que haja elaboração histórica dos sentidos e movimento no trabalho de identificação dos sujeitos. Segundo Gomes (2013), o intento de controle caminha em linha fronteiriça com a censura.

Neste aspecto, pode-se observar que o controle da expressão dos trabalhadores está naturalizado nas nossas práticas culturais. Se o assunto é um direito humano, a organização detém o poder de decisão sobre a fala dos trabalhadores contratados. Na perspectiva de Lima (2013), nossa longa história colonial e a fundação de um Estado nacional autocrático, assentado na escravidão, na cultura patriarcal e nos privilégios patrimonialistas, deixou como herança ao longo de nossa formação a "cultura do silêncio", ao invés da participação ativa dos cidadãos em uma opinião pública democrática. Reflexos dessa cultura também se fazem presente no contexto das organizações.

Some-se a isso o fato de que em cenários de crise e reestruturação há limitações que se impõem devido ao temor de críticas e danos à imagem, desconsiderando um direito fundamental. A falta de disponibilidade para se dedicar à pesquisa demonstra um contexto de trabalho em que não há tempo para uma reflexão sobre o trabalho, ou seja, os trabalhadores não podem se expressar sobre seu trabalho e devem se submeter a lógicas produtivas que os impedem de refletir (ANTUNES, 2011; 2018; LINHART, 2007). A pesquisa é vista como um prejuízo à rotina de trabalho e não como contribuição para o enfrentamento de questões que dizem respeito aos direitos humanos. Ademais, o pesquisador é um observador externo que precisa ser acompanhado no interior da organização, o que demanda a dedicação do trabalho de algum funcionário, responsável por preservar a imagem da organização e monitorar a atividade de pesquisa, verificando a adequação ao que estava previsto. Quanto à política interna para não participação em pesquisa, pode-se dizer que a interdição é uma forma já determinada pela organização para evitar a circulação de sentidos que escapam ao seu controle direto.

Dada a característica da pesquisa, com o aceite de sete organizações, decidimos interromper a abordagem a outras organizações porque teríamos condições de coleta de dados e análise suficientes para o estudo. As organizações que aceitaram participar na pesquisa têm pouco em comum. Entre elas, temos duas pequenas organizações de setores diferentes (empresa do setor publicitário e empresa do setor de recursos humanos), uma organização 
com atuação transnacional e de porte grande (empresa do setor elétrico), uma organização sem fins lucrativos e de grande porte (organização do setor de lazer, educação e cultura), uma organização nacional de grande porte (empresa do setor de transportes), duas organizações de médio porte (organização do setor de educação e empresa de tecnologia da informação). A disposição das assessorias de comunicação em contribuir para a pesquisa, considerada relevante, parece ter sido determinante para o aceite na participação da pesquisa. Disso resulta o empenho em aprová-la no interior da organização, convencendo as lideranças em processos sempre demorados. O fato de os dados poderem de alguma forma contribuírem para a gestão interna também despertou interesse.

\section{CONSIDERAÇÕES}

A realização de um estudo empírico na área de direitos humanos e organizações enfrenta dificuldades derivadas da falta de conhecimento que as organizações têm dos procedimentos de uma pesquisa científica e da disponibilidade de gestores em compreenderem a pesquisa para além de eventuais "danos" que se possam causar à imagem da organização. Tampouco se reconhece a pesquisa como contribuição ao conhecimento da sociedade. Ela ganha importância nos casos em que "agrega valor" às organizações. Uma pesquisa que visa levantar dados que ultrapassem os tradicionalmente publicados não é estimulada nem autorizada na maioria das organizações contatadas. Tal temor nos parece ser a afirmação da existência do controle sobre a fala de trabalhadores, que podem apresentar críticas às organizações, as quais se esforçam para manter um discurso alinhado às práticas de direitos humanos. A experiência para a entrada no campo nos mostra indícios da incidência da cultura do silêncio, tal como apontada por Lima (2013). Ademais, como assinala Antunes (2011), os trabalhadores continuam subordinados ao sistema produtivo criado pelas empresas, mesmo com mudanças nos paradigmas de gestão. As organizações que se dispuseram a participar da pesquisa representam uma minoria e parecem exercer menor controle discursivo na relação com os trabalhadores.

Nesse sentido, em termos gerais, observa-se uma dificuldade de integração das vozes do mundo do trabalho como parte dos discursos organizacionais, modulados e controlados para atender aos propósitos de consolidação de uma imagem positiva perante a opinião pública. Assim, a fala dos trabalhadores se relaciona à proteção que as organizações exercem 
de suas marcas (BARRY, 2007). Como resultado, tem-se uma contradição entre os objetivos organizacionais de respeito aos direitos humanos, a preservação da imagem e dos negócios em relação à expressão dos trabalhadores. Como apontam Figaro e Nonato (2014), a palavra proibida ou controlada constitui-se como norma estabelecida pela organização empresarial para reger o mundo do trabalho.

\section{REFERÊNCIAS}

AGAMBEN, Giorgio. O que é um dispositivo?. Outra travessia, Florianópolis, n. 5, p. 9-16, jan. 2005. Disponível em: <https://periodicos.ufsc.br/index.php/Outra/article/view/12576>. Acesso em: 23 maio 2020

ANTUNES, Ricardo. Os sentidos do trabalho: ensaio sobre a afirmação e a negação do trabalho. São Paulo: Boitempo, 2009.

ANTUNES, Ricardo. Adeus ao trabalho?: ensaios sobre as metamorfoses e a centralidade no mundo do trabalho. 15a . edição. São Paulo: Cortez, 2011.

ANTUNES, Ricardo. O privilégio da servidão: o novo proletariado de serviço na era digital. São Paulo: Boitempo, 2018.

BARRY, Bruce. Speechless: the erosion of free expression in the american workplace. San Francisco: Berret-Koehler Publishers, Inc, 2007.

BRASIL. Constituição da República Federativa do Brasil de 1988: promulgada em 5 de outubro de 1988. 56a. ed. São Paulo: Saraiva, 2020.

BRAVERMAN, Harry. Trabalho e capital monopolista: a degradação do trabalho no século XX. $3^{\mathrm{a}}$ ed. São Paulo: LTC, 2012.

BOUTET, Josianne. La vie verbale au travail : des manufactures aux centres d'appels. Toulouse: Octares, 2008.

BOLTANSKI, Luc.; CHIAPELLO, Eve. O novo espírito do capitalismo. São Paulo: Martins Fontes, 2009.

CARDOSO, Luis Antonio. A categoria trabalho no capitalismo contemporâneo . Tempo Social, São Paulo, v. 23, n. 2, p. 265-295, nov. 2011. Disponível em:

<http://www.revistas.usp.br/ts/article/view/12675>. Acesso em: 18 jan. 2020.

CARVALHO, José Murilo. O pecado original da República: debates, personagens e eventos para compreender o Brasil. Rio de Janeiro: Bazar do tempo, 2017.

CARVALHO, José. Murilo Cidadania no Brasil: o longo caminho. 25a. ed. Rio de Janeiro: Civilização Brasileira, 2019.

CAVEDON, Neusa Rolita. Antropologia para administradores. Porto Alegre: UFRGS, 2003.

DENZIN, Norman; LINCOLN, Yvonna. Handbook of qualitative research. 2a ed. Thousand Oaks: Sage, 2000. 
WEBER, Florence. A entrevista, a pesquisa e o íntimo, ou por que censurar seu diário de campo?. Horiz. antropol., Porto Alegre, v. 15, n. 32, p. 157-170, dez. 2009. Disponível em: $<$ http://www.scielo.br/scielo.php?script=sci_arttext\&pid=S0104-

$71832009000200007 \& \operatorname{lng}=$ en\&nrm=iso>. Acesso em 23 mai 2020.

FIGARO, Roseli. O mundo do trabalho e as organizações: abordagens discursivas de diferentes significados. In: Organicom, v. 5, n. 9, 2008, p. 90-100. Disponível em:

<http://www.revistas.usp.br/organicom/article/view/138986>. Acesso em 23 mai. 2020.

FIGARO, Roseli. Comunicação e Trabalho: binômio teórico produtivo para as pesquisas de recepção. Mediaciones sociales: revista de ciencias sociales y de la comunicación, $n^{\circ} 4$, primer semestre de 2009, pp. 23-49. Universidad Complutense de Madrid. Disponível em:

https://revistas.ucm.es/index.php/MESO/article/view/MESO0909120023A. Acesso em 21 ago. 2021.

FIGARO, Roseli. Comunicação e trabalho: implicações teórico-metodólogicas. Galáxia. Revista do Programa de Pós-Graduação em Comunicação e Semiótica. [S.1], n. 39, nov. 2018. Disponível em: <https://revistas.pucsp.br/galaxia/article/view/35905> Acesso em: 23 maio 2020.

FIGARO, Roseli.; NONATO, Cláudia. Comunicação e censura no mundo do trabalho. Interin.

Revista do Programa de Comunicação e Linguagem da Universidade Tuiuti do Paraná. [S.1.], v. 17, n. 1, 2014. Disponível em: 〈https://seer.utp.br/index.php/i/article/view/134〉. Acesso em: 5 maio 2020 .

FREEMAN, Robert Edward. Strategic management: stakeholder approach. New York: Cambridge University Press, 2000.

FREITAS, Riva Sobrado; CASTRO, Matheus Felipe. Liberdade de expressão e discurso do ódio: um exame sobre as possíveis limitações à liberdade de expressão. Sequência, Florianópolis , n. 66, p. 327-355, jul. 2013 . Disponível em:

<https://periodicos.ufsc.br/index.php/sequencia/article/view/28064> Acesso em 3 mai. 2020.

GOMES, Mayra Rodrigues. Deslocamentos dos discursos sobre supervisão. In: GOMES, Mayra Rodrigues (org.). Comunicação e controle: observações sobre liberdade, controle e interdição de expressão. São Paulo: Intercom, 2013, p. 25-41.

HARVEY, David. Condição pós-moderna: uma pesquisa sobre as origens da mudança cultural. 17 a. ed. São Paulo: Loyola, 2008.

LIMA, Venício. A censura disfarçada. In: LIMA, Venício.; GUIMARÃES, Juarez. Liberdade de expressão: as várias faces de um desafio. São Paulo: Paulus, 2013, p.87-109.

LINHART, Danièle. O indivíduo no centro da modernização das empresas: um reconhecimento esperado, mas perigoso. Trabalho \& Educação, Belo Horizonte, n. 7, jul./dez. 2000, p. 24-36. Disponível em: <https://periodicos.ufmg.br/index.php/trabedu/article/view/9201>. Acesso em 23 maio 2020.

LINHART, Danièle. A desmedida do capital. São Paulo: Boitempo, 2007.

LINHART, Danièle. Idéologies et pratiques managériales: du taylorisme à la précarisation subjective des salariés. Soc. estado., Brasília, v. 28, n. 3, p. 519-539, Dec. 2013 . Disponível em: <http://www.scielo.br/scielo.php?script=sci_arttext\&pid=S0102$69922013000300004 \& \operatorname{lng}=e n \& n r m=i s o>$. Acesso em 23 maio 2020. 
MARTINO, Luiz. A Interpretação do dado empírico no contexto das correntes teóricas em comunicação. In: BARBOSA, Marialva.; MORAIS, Osvando. (orgs.) Quem tem medo da pesquisa empírica? Disponível em:<http://www2.intercom.org.br/ebooks/arquivos/337a61995de8f72ef1d4842382986b6a.pdf.> São Paulo: Intercom, 2011, p.123-148. Acesso em 23 maio. 2020.

MELLO, Cristiane Maria Freitas. Direito de crítica o empregado nas redes sociais: e a repercussão no contrato de trabalho. São Paulo: LTR, 2015.

ORLANDI, Eni. As formas do silêncio: no movimento dos sentidos. 6a. ed. Campinas: Unicamp, 2015.

REBECHI, Cláudia Nociolini.; FIGARO, Roseli. A comunicação no mundo do trabalho e a comunicação da organização: duas dimensões distintas. Animus. Revista Interamericana de Comunicação Midiática, [S.1.], v. 12, n. 24, dez. 2013.. Disponível em:

<https://periodicos.ufsm.br/animus/article/view/10811>. Acesso em: 3 maio 2020.

RUGGIE, John. Quando negócios não são apenas negócios. São Paulo: Planeta Sustentável, 2014. SAMPIERI, Roberto Hernandez; COLLADO, Carlos Fernandez;. LUCIO, Maria del Pilar Baptista. Metodologia de pesquisa. São Paulo: McGraw Hill, 2006.

SANTOS, Milton. Por uma outra globalização: do pensamento único à consciência universal. São Paulo: Record, 2000.

SANTOS, Luís Henrique Sachi; KARNOPP, Lodenir Becker. Ética e pesquisa em educação: questões e proposições às Ciências Humanas e Sociais. Porto Alegre: UFRGS, 2017.

ZACCARELLI, Laura Menegon; GODOY, Arilda Schmidt. Perspectivas do uso de diários nas pesquisas em organizações. Cad. EBAPE.BR, Rio de Janeiro, v. 8, n. 3, p. 550-563, set. 2010 Disponível em: <http://www.scielo.br/scielo.php?script=sci_arttext\&pid=S1679-

$39512010000300011 \& \operatorname{lng}=$ en\&nrm=iso $>$. Acesso em 2 maio 2020.

Original recebido em: 21 de junho de 2020

Aceito para publicação em: 01 de outubro de 2021

\section{Fernando Felício Pachi Filho}

Doutor em Linguística (Unicamp), com pós-doutorado em Comunicação e Artes (ECA-USP), e mestre em Comunicação e Semiótica (PUC-SP). Professor de Comunicação na Faculdade de Tecnologia Termomecanica e membro do Centro de Pesquisa em Comunicação e Trabalho (CPCT) da

ECA-USP.

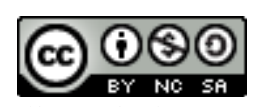

Esta obra está licenciada com uma Licença

Creative Commons Atribuição-NãoComercial-CompartilhaIgual 4.0 Internacional 